\title{
Constituição: resiliência e relevância
}

\author{
Paulo Thadeu Gomes da Silva* \\ Enfim, cada um o que quer aprova, o senhor sabe: \\ pão ou pães, é questão de opiniães... \\ João Guimarães Rosa, Grande sertão veredas
}

\section{Introdução}

Escrever um trabalho científico, seja de que formato for, é empresa de grande risco, pois o trabalho solitário impede o exercício da crítica voltado para si mesmo, alerta já feito por Freud (1996:30).

Esse óbice faz com que não se possa ter à vista os defeitos do trabalho, desde sua estrutura formal até seu conteúdo. A tarefa se torna, então, mais árdua quanto mais se constata a complexidade do mundo da vida. Esta, a vida, que na feliz metáfora de Calvino (2002:205) pode ser comparada a uma alcachofra, realidade com estratos densamente sobrepostos, e é a partir dela que se percebe a complexidade da sociedade.

Respostas a perguntas ontológicas, desta feita, se mostram quase impossíveis de formular, causando frustração no sujeito que conhece. Efeito que se espraia a todos os eventos da sociedade moderna e que pode ser traduzido pela falta de condições de possibilidade para se ir em busca do fundamento - Zu Grund gehen - , seja porque não há mais fundamento, seja porque não há apenas um único fundamento, preocupação que de resto, na área jurídica, mostra sua cara de forma tímida e quando muito na filosofia do direito.

\footnotetext{
* Especialista em administração e proteção dos direitos humanos pelo Institut International d'Administration Publique, Paris; mestre em direito pela Pontifícia Universidade Católica (PUC-Rio); doutor em direito pela PUC-SP; procurador regional da República em São Paulo.
} 
O problema é que aqui vamos propor descrições afetas à teoria constitucional, em especial a brasileira, sede que se marca pela falta de produção de novos saberes, impregnada de um dogmatismo "mais do mesmo" e de certos pensamentos caducos iluministas jacobinos e/ou de pessimistas de plantão que apostam todas as fichas na alopoiese do sistema jurídico.

A simplificação do pensamento que acaba por operar um reducionismo na teoria constitucional obsta o nascimento de uma reflexão que leve em conta a complexidade do direito e da política e das relações que se estabelecem entre ambos. Como afirma Prado Jr. (2004:221) "não se trata de suspender ou de ultrapassar o conflito enunciado na frase, mas de fazer trabalhar a tensão que a atravessa".

Lúcido e pleno de rigor científico e exceção a esse quadro homogêneo é o pensamento de Vilanova (2003:373), que escreve que "a política e o direito que reciprocamente se implicam têm isso em comum, em face da multiplicidade heterogênea da realidade social: são normas que politicizam, ou juridificam conteúdos", ou seja, mantêm entre eles uma relação normativa.

Na concretização dessas relações há sempre um incremento no número delas mesmas, pois os elementos que compõem ambos os sistemas não são numeráveis, o que produz como resultado a impossibilidade de se indicar todas as relações que se perfazem entre os dois sistemas. Essa observação influencia diretamente tanto a produção de decisão coletivamente vinculante, quanto a formação da jurisprudência. O político, como num passe de mágica, "descobre" que no jurídico há possibilidade de se proteger o direito formal e material da oposição, enquanto do seu lado, o jurídico, "se descobre" passível de reparar a política formal e material, recrudescendo sempre e sempre as possibilidades de relações a serem estabelecidas entre os dois.

Essas descobertas podem ser tidas na conta de testes pelos quais a Constituição, numa democracia, ${ }^{1}$ tem que passar, pois é neles que vai se exprimir o poder constitucional de reforma e o poder de interpretação constitucional por quem é competente para tanto. A depender do conceito de Constituição do qual se parta para se fazer esses testes está a ideia de resiliência e de relevância do próprio texto constitucional. O seu grau de institucionalização será tanto maior quanto maior for a resiliência e a relevância de seu texto.

A descrição mais adequada desse evento talvez dependa de uma certa transdisciplinaridade que marca a ciência moderna, quando se exige do observador conhecimentos além-fronteira, ou uma abertura cognitiva a outros saberes. É o que se persegue neste artigo.

\footnotetext{
${ }^{1}$ Conceitos de democracia existem numa profusão de causar inveja mesmo ao deus da fartura, contudo, para os fins deste artigo, pode-se delineá-lo a partir da ideia de Niklas Luhmann (1997), para quem democracia é a existência do código binário do sistema político representado por governo/oposição.
} 


\section{Resiliência e relevância: significados}

Resiliência e relevância são conceitos atavicamente imbricados, um decorre do outro, numa relação contínua e inabalável. O estudo da resiliência da Constituição tem a ver com a capacidade que o texto constitucional possui para, formal e materialmente, continuar a limitar o poder e a proteger os direitos fundamentais, mesmo após as reformas constitucionais e a interpretação constitucional, portanto, não se trata da capacidade do texto constitucional de voltar à sua forma original, mas sim da capacidade de se adaptar facilmente às mudanças; o da relevância diz com a capacidade do texto constitucional de continuar sendo o protagonista no processo de desenvolvimento da sociedade moderna, aí incluído o Estado.

\section{Resiliência}

Os fenômenos que atingem o texto constitucional e que podem ou não produzir a sua resiliência são de duas ordens: a reforma constitucional e a interpretação constitucional. A única diferença entre ambos os processos é que no primeiro a norma, integral ou parcialmente, deixa de existir e é substituída por outra; no segundo, a norma continua a existir, no entanto, o que muda é a atribuição de significado a ela.

Em geral a forma de se alterar o texto constitucional por meio de reforma a ser levada a cabo pelo sistema político é, paradoxalmente, a mais criticada, seja pelos cientistas políticos, seja pelos juristas. O paradoxo se qualifica pela crítica endereçada ao sistema competente, o político - numa discussão sociológicoconstitucional já clássica e mofada que reveste-se de problema de legitimidade. A competência do sistema político para alterar o texto constitucional vem prevista, autologicamente, no próprio texto que se pretende reformar. Por certo que a crítica é dirigida com maior ênfase à quantidade de emendas que reformam o texto constitucional, antes do que ao sistema mesmo com atribuição para tal. Contudo, quando se generaliza o ataque, outros alvos vão embutidos.

O mesmo não acontece quando a alteração do texto constitucional é operada pelo sistema jurídico que, mediante processos nos quais se manifesta a vontade dos 11, confere novos significados às normas constitucionais, significando e ressignificando conceitos até então lá expostos e consolidados. ${ }^{2}$ De forma geral, ao

\footnotetext{
${ }^{2}$ Por meio da interpretação constitucional relativizam-se, inclusive, direitos tidos na conta de cláusula pétrea, v.g., direito adquirido que não se manifesta com relação a regime jurídico e coisa julgada inconstitucional: o que é proibido ao sistema político é permitido ao jurídico.
} 
menos no Brasil, não se discute a respeito da vontade original dos fundadores, mas sim, tenta-se elaborar uma ideia de Constituição que vive, é vivente - ou sobrevivente, com o perdão da ironia. Essa forma de alterar o texto constitucional dificilmente sofre crítica, dos cientistas políticos, certamente porque eles não conhecem, com propriedade mínima, os meandros do processo de interpretação, com sua linguagem técnica própria, e dos juristas porque estes parecem se conformar - e se orgulhar - da alteração produzida pelo sistema jurídico, como se fosse um jogo de forças atuantes sobre um mesmo objeto do qual se reclama, se não a paternidade, ao menos a propriedade. A impressão que fica é que esse tipo de mudança é autorizado, como se chancelado pelas opiniões de autoridade.

As críticas feitas com relação ao primeiro modo de se alterar o texto constitucional são inócuas, não conseguem produzir qualquer tipo de autocrítica - ou seria autoimunização - no sistema originário, isto é, o político; no máximo constituem-se em noise no processo comunicativo. Isso se deve a que a reflexividade se imponha como característica da sociedade moderna, e que se traduziria pela reforma da reforma da reforma constitucional, e assim sucessivamente, num processo contínuo, inexorável e inestancável, ou talvez seja mesmo ao fato de que haja, na sociedade moderna, um esquecimento da política que é feita em sistema próprio e, por mais que queira Luhmann dizer o contrário, de forma solipsística, sem abertura cognitiva. O resultado é já esperado: os tribunais constitucionais ou similares, como é o caso do Supremo Tribunal Federal, se tornam o depositário da fé e da crença da sociedade, estas deslocadas, indevidamente, da política para o jurídico. E é aí que entra em cena a discussão sobre o conceito de Constituição, ou sobre qual seria o conceito mais adequado de Constituição ante a esse problema tão complexo que é o da reforma de seu texto, ou seja, para tentar demonstrar ou construir uma ideia de Constituição que possa ser resiliente mesmo após sofrer processos intensos de mudança de seu texto por meio da reforma feita pelo sistema político.

Se há críticas com relação ao primeiro modelo, com relação ao segundo elas não existem, já que falta a ela constatação, o objeto constatado, ou seja, a própria crítica. Essa ausência de crítica à alteração do texto constitucional operada pelo sistema jurídico quando do exercício da interpretação pode ser decorrente do que diz a própria norma constitucional, segundo a qual o Supremo Tribunal Federal é o guardião da Constituição. Todavia, o mesmo argumento valeria para o sistema político, pois a ele é conferida, expressamente, a competência para reformar o texto constitucional. Poder-se-ia, nesse passo, perscrutar os significados do conceito "guarda da Constituição", chegando-se mesmo à conclusão de que o Supremo Tribunal Federal seria o protetor do texto contra as investidas levadas a efeito por outros poderes, federais e/ou estaduais, contra o texto constitucional; poder-se-ia argumentar em prol de que o Supremo Tribunal Federal fosse o defensor do mes- 
mo texto, exercício esse puramente dogmático de repetição e por isso mesmo sem qualquer nova contribuição à teoria constitucional, desde que a polêmica Kelsen/ Schmitt foi vencida pelo primeiro.

Outra possibilidade de descrição desse evento é aquela atrelada à ideia de que uma reforma constitucional realizada pelo sistema político é, simbolicamente, mais abrangente e mais danosa à Constituição - e não à sociedade - do que aquela concretizada via interpretação constitucional. Aqui também se manifesta um paradoxo. É que a ideia de algo que é simbólico tem a ver com um intenso poder de legislar em detrimento do jurídico, isto é, legisla-se sem a preocupação, ou mesmo a possibilidade, de se concretizar a lei então elaborada, prejudicando-se, dessa maneira, o jurídico-instrumental. Isso é a legislação simbólica, segundo Marcelo Neves (2007:23). Trocando em miúdos, faz-se a lei dissociada das estruturas sociais pertencentes à realidade.

Contudo, quando se trata de reforma constitucional, e ao menos em sua generalidade, é ela realizada exatamente para adequar o texto da Constituição à realidade presente, que ao tempo de sua elaboração não existia, embora o próprio $\mathrm{Ne}$ ves escreva que mesmo a reforma constitucional pode ser exemplo do simbólico. É o caso, por exemplo, da recente e crescente internacionalização de que sofrem os textos constitucionais, dos quais o brasileiro não é exceção, e que indica uma resposta normativa à demanda produzida pela realidade. A legitimidade de que se cuida, portanto, é já a de uma Constituição que serve de norma-parâmetro a gerações que não a elaboraram, como se estas estivessem sendo guiadas por uma dead hand. ${ }^{3}$

Assim, se a noção de legislação simbólica vale para o ordenamento infraconstitucional, para o ordenamento constitucional, em relação específica às emendas constitucionais, não parece se manifestar e impregnar o poder constituinte revisor, sendo certo que no nível constitucional a constitucionalização simbólica pode ser manifesta quando da elaboração do texto constitucional pelo poder constituinte originário, quando então há a factível possibilidade de se produzir um texto total ou parcialmente dissociado da realidade que o circunda, o que gera efeitos teóricos, por exemplo, no campo de estudo do constitucionalismo, sede onde surge argumento sobre a existência de Constituição sem constitucionalismo. Isso não exclui a possibilidade de, sob o pálio da exceção, mas não da regra, se produzir uma reforma constitucional que positive norma apenas simbolicamente adequada à realidade, como faz exemplo a positivação do direito à moradia como direito social.

Também com referência à problematização do que é simbólico, há um texto de Corwin (1936:1071-1085), para quem, no contexto norte-americano, a Constitui-

\footnotetext{
${ }^{3}$ A ideia é de Stephen Holmes (1993:195-240).
} 
ção pode ser tomada na conta de instrumento e de símbolo. ${ }^{4}$ Como instrumento, Corwin argumenta que a Constituição, amparada na visão científica de instrumento que conota o futuro e o que deve ser feito no futuro, é um instrumento do poder popular (soberania, se quiser) para o alcance do progresso. De outra parte, o simbolismo constitucional americano olha para o passado e se liga às concepções que antedatam o surgimento da ciência e sua crença numa causação manejável e predizível. Ainda segundo Corwin, enquanto o instrumento constitucional existe para energizar e canalizar o poder público, é função do simbolismo constitucional proteger e tranquilizar o interesse privado contra o poder público.

No texto constitucional americano, Corwin indica como lugar de manifestação do instrumento constitucional o preâmbulo da Constituição, vazado nos termos: "Nós, o povo dos Estados Unidos, em ordem a formar a mais perfeita união, estabelecer justiça, assegurar a tranquilidade doméstica etc..."; como sede do aparecimento do simbolismo constitucional, "a enumeração na Constituição de certos direitos não deve ser construída para negar ou criticar outros retidos pelo povo".

Como se pode perceber, se não há uma preocupação de Corwin em depurar conceitos, como faz Neves, há a presença, mais uma vez, da distinção entre instrumento/simbólico e/ou norma/realidade. Essas distinções permitem pensar que, embora a análise de Corwin tenha sido feita levando em consideração a Constituição norte-americana, a mesma descrição pode ser conferida tomando-se por base a Constituição brasileira.

Uma primeira tarefa para a consecução dessa empresa pode ser a identificação do que venha a ser instrumento e simbólico no texto constitucional pátrio. O texto constitucional brasileiro possui normas que guardam relação de pertinência com o que se entende por instrumento e simbólico. O preâmbulo, por exemplo, preceitua no mesmo sentido que o norte-americano, ainda que no nacional a redação seja mais ampla e mais atual; o $\S 2^{\circ}$ do art. $5^{\circ}$, de sua vez, pode ser relacionado ao simbólico, com a ressalva de que o texto constitucional norte-americano se refere a outros direitos retidos pelo povo, ${ }^{5}$ enquanto o brasileiro prescreve outros direitos e garantias decorrentes do regime e dos princípios adotados pela Constituição ou dos tratados internacionais em que a República Federativa do Brasil seja parte.

Por certo que a concepção de Corwin, datada da década de 1930, além de conter uma espécie de fé cega no progresso, característica da ciência de então, ainda se impregnava de um conteúdo privatista dominante, vale dizer, o simbólico se referia, especificamente, à ideia de direito individual, o que não pode ser mais

\footnotetext{
${ }^{4}$ Aqui é importante destacar que os termos simbólico, símbolo e simbolismo apresentam a marca da ambiguidade como característica, conforme Marcelo Neves.

${ }^{5}$ Embora no processo constituinte norte-americano o povo dele não tenha participado, conforme Ferreira Filho (2003:45).
} 
aceito nos tempos atuais, uma vez que a compreensão hoje, de direitos fundamentais perpassa por outras categorias de direitos, conforme o que se pode extrair da cláusula universalizante de sentido positivada na norma do art. 5o, inciso XXXV, da Constituição Federal.

A utilidade das lições de Corwin para o entendimento do simbólico na Constituição brasileira reside em que delas se pode extrair duas conclusões: a manifestação da distinção instrumento/simbólico, que de sua vez remete à distinção entre norma e realidade; desde que se tome como adequada a distinção que vem de ser escrita, a compreensão da Constituição como uma verdadeira face de Jano, na qual vêm inseridas outras duas distinções: do ponto de vista temporal, passado e futuro; e do ponto de vista orgânico dos poderes, gubernaculum e jurisdictio.

O processo constituinte brasileiro que elaborou a Constituição, ainda hoje, mesmo que por poucas vozes, é tachado de ilegítimo, já que a Assembleia que produziu o documento não foi exclusivamente constituinte, mas sim congressual. As poucas e fracas vozes que de quando em vez se manifestam afirmando a ilegitimidade do processo indicam um aspecto simbólico positivo para o texto constitucional, espasmos de sua serventia como instrumento. É que o documento escrito em 1988 possui uma força normativa própria que, se não chega a ser uma lei fundamental de Bonn e se não produz um mais adequado exercício da atividade política coordenado com os preceitos constitucionais, não deixa de ter valor, por exemplo, como norma-parâmetro que no controle de constitucionalidade vem produzindo interpretações que preenchem o vácuo constitucional deixado pelos outros poderes: o Executivo e o Legislativo, que forçam um conserto no agir desses mesmos poderes em relação à Constituição. ${ }^{6}$

Essa intensa atividade judicial de cobrir buracos deixados na estrada pelos outros poderes pode se referir tanto à ação quanto à omissão inconstitucional, e se revela um enfraquecimento da ideia de Constituição simbólica no sentido que lhe atribui Neves, tendo em vista a real efetivação das normas constitucionais. Demonstra outro lado, representado pelo reforço da Constituição como instrumento, desde que se pense que ao menos o Supremo Tribunal Federal tem agido, em geral, de acordo com as normas constitucionais, o que produz um tardio movimento que pode ser chamado de ativismo judicial, embora diferente do que acontece nos Estados Unidos, onde a interpretação constitucional funciona como um necessário mecanismo de reforma do texto, tendo em vista a dificuldade de se alterar por emenda a Constituição daquele país, aqui o nascente ativismo judicial existe simultaneamente com a produção de emendas constitucionais.

\footnotetext{
${ }^{6}$ Ver o caso das medidas provisórias e da abertura de créditos extraordinários, adiante analisados.
} 
Uma das razões - há várias - para o constante acionamento do mecanismo da reforma e da interpretação constitucional pode ser a que condiz com o próprio momento de elaboração do texto constitucional brasileiro, quando então as demandas, bastante reprimidas pelo estado de exceção que se instaurou no país, começaram a jorrar e a serem canalizadas pelos fatores reais de poder presentes no respectivo processo, causando, com isso, a par de uma explosão de litigiosidade, um descompasso entre norma e realidade, agravado pelo annus mirabilis de 1989, momento histórico que fez cair por terra qualquer tentativa de se descrever, prospectivamente, a sociedade moderna, além de produzir o efeito da economia se tornar a protagonista dos eventos, a par do lamentável esquecimento da política, o que, na feliz frase de Corwin, escrita em outro contexto, em artigo já citado, faz com que "the symbol of the many becomes the instrument of the few".

O que parece merecer destaque na descrição da distinção instrumento/simbólico, norma/realidade é a relação que se estabelece entre os pares da dicotomia: é relação de coordenação ou de subordinação? A resposta não é de fácil alcance, contudo algumas problematizações podem ser feitas na tentativa de se esclarecer a indagação.

Nos países centrais da modernidade há um exercício autônomo da atividade política, como se o sistema político compreendesse, por razões várias e de antemão, como deve atuar para que esse mesmo exercício não malferisse, por ação ou por omissão, a Constituição. Portanto, nesses países o caráter instrumento da Constituição sempre permanece, se não intocável, ao menos com força suficiente a se autorrenovar. $\mathrm{O}$ mesmo se pode afirmar com relação ao simbólico da Constituição, considerado aqui na concepção de Corwin, segundo a qual ele se representaria pela oposição dos direitos individuais frente ao poder público, do que se conclui que a relação entre instrumento/simbólico é de coordenação.

Em países como o Brasil o mesmo não ocorre. Aqui há uma prevalência do simbólico contido na subdistinção instrumento/simbólico ${ }^{7}$ referente à norma/realidade em relação ao instrumento propriamente dito, ou seja, a produção legiferante, aí incluída a Constituição, é simbólica no sentido que lhe atribui Neves, isto é, dissociada da realidade, ainda que produzido o documento álibi para fazer frente a ela. No que diz com o simbólico no sentido atribuído por Corwin, pode-se

\footnotetext{
${ }^{7}$ A ideia de subdistinção, criada neste artigo, tenta englobar as duas noções de simbólico, a de Marcelo Neves e a de Edward Corwin, as quais, embora materialmente diferentes entre si, não são antitéticas, e porque são formalmente iguais e materialmente se complementam, podem ser incorporadas no mesmo esquema da distinção, desde que sejam consideradas uma subdistinção da distinção principal. Assim, tem-se: instrumento (instrumento/simbólico)/simbólico. Aqui defende-se a manifestação, na realidade brasileira, das duas concepções de simbólico, portanto, contrária, em parte, à ideia de Neves de que o sistema jurídico brasileiro é alopoiético: não se trata, por óbvio, de não se admitir uma certa alopoiese no sistema jurídico brasileiro, mas apenas de considerar a ideia de que ele, sistema jurídico, só se autorreproduz alopoieticamente, um exagero.
} 
afirmar que ele sofre de anemia institucional, porém existe, embora apresente um quadro de recrudescimento de seu sentido, vive momentos de refluxo, o que pode ser ilustrado pelo autêntico efeito vai-e-vem da afirmação histórica dos direitos humanos no contexto nacional, de sua vez causado pela existência de uma fraca esfera pública. A relação, portanto, não é de coordenação, mas sim de subordinação, quase uma hierarquia entre os pares que compõem a subdicotomia, o que não significa que apenas o simbólico se manifeste.

Uma distinção desemboca noutra. A Constituição como a face de Jano, divindade romana cuja principal característica era a prudência, passa a ser reflexo da primeira distinção representada pela dupla instrumento/simbólico e/ou norma/ realidade. Jano tinha a capacidade de olhar, simultaneamente, para o passado e para o futuro. É o que se passa, metaforicamente, com o texto constitucional, seja com relação à dimensão temporal, seja com referência à dimensão orgânica de funcionamento dos poderes.

Do ponto de vista temporal a Constituição tem que voltar os olhos para o passado e para o futuro. ${ }^{8}$ No primeiro caso quando positiva em seu texto as chamadas cláusulas pétreas, as quais se caracterizam por sua eternidade, como passado que se faz presente agora e no futuro; no segundo caso quando positiva em seu texto normas de conteúdo finalístico - e aqui não se vai discutir a respeito da polêmica classificação dos programas jurídicos serem apenas condicionais ou também de fins - , voltadas, prospectiva e redundantemente, para o futuro, contudo, com sua concretização requerida já no presente. O problema da temporalidade se apresenta distintamente a cada sistema, vale dizer, os sistemas político e jurídico possuem temporalidades diferentes. Diz respeito à relevância da Constituição.

Do ponto de vista orgânico do exercício dos poderes sobressai a distinção governo/jurisdição, ou mais especificamente, a Constituição como parâmetro da atuação instauradora realizada pelo governo e da atuação reparadora levada a cabo pelo Judiciário, o que será exposto sob a rubrica "um certo ativismo judicial tardio". Tem a ver com a resiliência da Constituição.

\section{Um certo ativismo judicial tardio}

Não há como escrever sobre o termo ativismo judicial sem mencionar o seu percurso temporal e semântico na teoria constitucional norte-americana, berço da discussão sobre a matéria. Há uma profusão tal de artigos e votos de juízes nos quais o termo é mencionado, descrito e normatizado que se torna mesmo impossível de se esgotar a análise de sua citação.

\footnotetext{
${ }^{8}$ Sobre as distintas temporalidades dos sistemas jurídico e político, ver Gomes da Silva (2005).
} 
Para os fins deste artigo reputa-se suficiente tomar como parâmetro de estudo o artigo de Keenan D. Kmiec, intitulado "The origin and current meanings of judicial activism". ${ }^{9}$ Nesse artigo o autor traça pequena história de emprego do termo na imprensa, na academia e no Judiciário para, ao final, indicar cinco possíveis definições do que venha a ser considerado ativismo judicial. São elas: cassar ações constitucionais de outros poderes que forem ajuizadas; ignorar ou desconsiderar precedente (vertical $v$. horizontal precedente; constitucional $v$. legal $v$. common law precedentes); legislação judicial; não partir de metodologia interpretativa aceita; julgamento com resultado dirigido e/ou orientado.

A primeira definição refere-se ao exercício do controle de constitucionalidade pelo Supremo Tribunal Federal, o mesmo que judicial review na Suprema Corte norte-americana; a segunda diz com a doutrina do stare decisis do sistema jurídico daquele país, pela qual há a formação do precedente vertical, da Suprema Corte em relação às cortes inferiores, e do precedente horizontal, na jurisprudência da própria Corte, além dos precedentes de caráter constitucional, legal ou costumeiro; a terceira definição tem a ver com a falha no processo de interpretação constitucional causada pela não observação dos cânones interpretativos; e a última liga-se à antiga preocupação, transformada em doutrina, segundo a qual os juízes não podem julgar tendo em vista motivo ulterior para emitir a decisão e nem se desviar de uma linha básica de correção.

Com relação ao sistema jurídico brasileiro, a definição primeira, uma vez acatada pela teoria constitucional tornaria o Supremo Tribunal Federal um exemplo lídimo de ativista judicial só porque exercita o controle de constitucionalidade, fazendo-se de forma direta e indireta, com recurso a técnicas sofisticadas de interpretação constitucional, de modo que parece ser adequada, como regra, a definição proposta, especificamente com referência àqueles casos jurídicos cujas decisões proferidas irradiam seus efeitos na política material.

As segunda e quarta definições não parecem ser aplicáveis ao sistema aqui implementado, uma porque a doutrina do stare decisis não existe, ao menos oficialmente, nas plagas jurídicas brasileiras, e o instituto da súmula vinculante ainda engatinha, recém-nascido que é, embora se possa afirmar que mesmo o precedente no direito constitucional norte-americano não é de todo rígido, conforme expressamente lançado em Lawrence $v$. Texas, ${ }^{10}$ e no direito constitucional brasileiro exista sempre a possibilidade de se rediscutir determinada interpretação constitucional firmada anteriormente, de acordo com interpretação grafada na ADIn no 4.048-1/

\footnotetext{
${ }^{9}$ Os conceitos descritos nesse artigo o são de maneira mais pormenorizada que aqueles referentes à judicialização da política e encontrados em Tate e Vallinder (1995).

${ }^{10}$ Lawrence v. Texas, 539 US (2003): "The doctrine of stare decisis is essential to the respect accorded to the judgments of the Court and to the stability of the law. It is not, however, an inexorable command", p. 16 do voto do Justice Kennedy, pela Corte.
} 
DF, ${ }^{11}$ e a duas porque não há, propriamente escrevendo, cânones da interpretação constitucional nacional, havendo, quando muito, determinados princípios de interpretação que, uma vez não respeitados, não torna o Supremo Tribunal Federal ativo judicial, mas apenas eiva a interpretação operada com a pecha de errada - pense-se na interpretação da Constituição às tiras, e não sistematicamente.

A última definição, que condiz com a possibilidade do juiz julgar orientado pelo resultado de sua decisão, especialmente no que toca aos efeitos sociais dela advindos, e se no debate constitucional norte-americano se refere ao juiz que é liberal ou conservador, já teve espasmo de existência no Brasil, ao menos em uma de suas variantes, particularmente no período imediato pós-ditadura militar, mais conhecido por transição democrática, no qual se produziu bastante material jurídico referente às motivações ideológicas da sentença e quando então o debate a respeito da orientação político-ideológica dos juízes era presente e forte, todavia, atualmente o tema parece ter perdido fôlego, ainda que, na seara constitucionalpenal o debate se mantenha aceso entre garantistas e não garantistas.

Resta a definição que identifica o ativismo judicial com a legislação judicial. Esta parece se aplicar a uma eventual ideia de que o Supremo Tribunal Federal pode ser enquadrado como uma Corte ativista judicial ou ativa judicialmente, desde que se pense que no seu cotidiano decisório, quando, ao interpretar a Constituição, cria normas para a sociedade em geral, ainda que no varejo do caso individual, e não no atacado do caso objetivo, referentes tanto a direitos individuais quanto a direitos sociais.

O mais relevante, entretanto, nessa práxis decisória, vem sendo a institucionalização do Supremo Tribunal Federal como instância deliberativa dos grandes temas atinentes à sociedade brasileira, o que se não é novidade no que se refere à produção de efeitos na política formal, já começa a produzir efeitos recentes na política material, seja ela constitucional ou ordinária.

A ideia de ativismo judicial, portanto, atribua-se qualquer significado a ela, presente no debate constitucional norte-americano, se espraiou de uma tal maneira que hoje bem se pode afirmar a sua presença na maioria dos países ocidentais. No Brasil não é diferente. País que teve sua história constitucional marcada pela presença manifesta e latente de crises, traduzidas na decretação useira e vezeira de estados de exceção, background nada propício à criação de um caldo cultural constitucional, vive hoje uma normalidade democrática na qual o debate existe e serve ao recrudescimento da esfera pública da sociedade brasileira. O Supremo Tribunal Federal não poderia passar incólume por esse processo. Tímida no início

\footnotetext{
${ }^{11}$ Requerente: Partido da Social Democracia Brasileira (PSDB). Requerido: presidente da República, relator ministro Gilmar Mendes.
} 
do período de democratização dos anos 1980, é nessa década que o tribunal se firma como precursor de um ativismo judicial de maneira mais forte e, ao que parece, solidificada sobre estruturas de decisão que vão além dos casos concretos para espargir seus efeitos de forma erga omnes.

Como se pode perceber, a hessiana força normativa da Constituição depende da concepção que se tem do próprio texto escrito. Se for tomado na conta de um documento com força suficiente para produzir eventos na sociedade de acordo com os princípios ali positivados, é crível que a força normativa intrínseca a ele se manifeste.

A concretização dessa aparente força metafísica da Constituição é realizada pelas instituições de uma determinada sociedade. No caso do Brasil, que é o que interessa neste artigo, o responsável por essa tarefa tem sido o Supremo Tribunal Federal, por duas razões: tem, paulatinamente, transmudado a sua própria interpretação constitucional; produz, com esse modo de proceder, um grau cada vez mais alto de institucionalização de si próprio.

Um caso paradigmático dessa atuação é representado pela decisão cautelar proferida na ADIn no 3.964-4/DF, ${ }^{12}$ na qual ficou assentado que o Poder Executivo não pode reeditar, na mesma sessão legislativa, medida provisória revogada. $\mathrm{O}$ tema é bastante complexo e por isso mesmo comporta uma descrição mais pormenorizada. Tratou, na espécie, de se perquirir a respeito do poder constitucional do chefe do Executivo Federal de revogar medida provisória uma vez editada para, logo depois, reeditá-la, e nesse meio tempo a pauta do Legislativo desbloquearse-ia pela revogação operada. Os ministros, por maioria, entenderam que tal ação configurava fraude à Constituição, já que ela mesma proibia essa prática.

O fundamento adotado foi a violação ao disposto nas normas do art. $62, \S 10$, da Constituição, que proíbe a reedição, na mesma sessão legislativa, de medida provisória que tenha sido rejeitada ou que tenha perdido sua eficácia por decurso de prazo. Embora a redação ali expressa não faça menção à hipótese de revogação da medida provisória pelo próprio agente político que a editou, a maioria vencedora entendeu que era caso de se interpretar a norma como que contemplando, implicitamente, a hipótese, a despeito do argumento proferido pelo ministro Eros Grau de que o tribunal estaria usurpando o poder constituinte derivado ao criar nova figura não estampada no texto.

O caso ganha contornos de dramaticidade porque traz à tona uma abordagem, no dizer de Posner (2005), ${ }^{13}$ mais agressiva do Judiciário quando em análise

\footnotetext{
${ }^{12}$ Requerente: Partido da Social Democracia Brasileira (PSDB). Requerido: presidente da República, rel. ministro Carlos Britto.

13 "One is for the Justice to accept the political character of constitutional adjudication wholeheartedly and vote in cases much as legislators vote on bills. The other alternative is, feeling bashful about being
} 
de ato político. É que envolvida está, também, no desenrolar da argumentação, a norma do art. 62, § 6o , da Constituição, que determina que se a medida provisória não for apreciada em até 45 dias contados de sua publicação, entrará em regime de urgência, subsequentemente, em cada uma das Casas do Congresso Nacional, ficando sobrestadas, até que se ultime a votação, todas as demais deliberações legislativas da Casa em que estiver tramitando (grifou-se).

Com efeito, esse modo de atuar do Executivo, ao editar, revogar e reeditar, na mesma sessão legislativa, uma mesma medida provisória, com redação se não idêntica, similar em quase todos os seus aspectos, dá mostras de efetiva possibilidade de controle da agenda do Legislativo por parte do primeiro, o que, se numa apreciação jurídica representa fraude à Constituição e quebra do princípio da separação e harmonia dos poderes, numa apreciação política significa frustrar a própria ação política, a própria autorreprodução do sistema político, a própria política material, e não mais apenas formal, frustração essa causada pelo sistema político a ele mesmo e para a qual não parece haver outro meio de defesa, nem mesmo uma suposta autoimunização, que não o recurso ao sistema jurídico.

Esse evento, então, tem que ser compreendido como, de um lado, exemplo de aplicação judicial de princípio formal positivado no texto constitucional, e de outro, exemplo de frustração ou bloqueio de funcionamento do sistema político pelo próprio sistema político, o que, se não foi pensado pelo legislador constituinte derivado, responsável pela alteração do texto constitucional inicial para nele positivar normas que de fato e de direito limitassem o poder de editar medida provisória - fato esse que permite a atual interpretação constitucional da mesma norma - , pode ser considerado fruto da complexidade dinâmica da política materialmente considerada. O que vem de ser escrito é traduzido na asserção de que o sistema jurídico pode, ao interpretar dispositivo constitucional que prescreva limitação formal ao exercício do sistema político, interferir diretamente na ação política levada a cabo pelos agentes responsáveis. É válido pensar que a decisão de que se trata, por exemplo, produziu efeito positivo não só ao resguardar o "direito" do Legislativo a tomar as rédeas do estabelecimento de sua própria agenda, o que poderia ser considerado um efeito formal da decisão, mas também ao assegurar talvez aquilo que seja mais caro ao processo legislativo, que é a obtenção de consenso majoritário sobre a deliberação - discussão e votação - das matérias a

a politician in robes, to set himself or herself a very high threshold for voting to invalidate on constitutional grounds the action of another branch of government. The first, the 'agressive judge' approach, expands the Court's authority relative to that of other branch of government. The second, the 'modest judge' approach, tells the Court to think very hard indeed before undertaking to check actions by other branches of government." 
ele apresentadas, consenso esse que ainda não existe se a medida provisória não foi apreciada pelo Poder Legislativo. ${ }^{14}$

Essa forma de compreensão judicial é evento novo na jurisprudência da Corte, pois possui significado que vai muito além de um suposto controle dos requisitos formais exigidos para a edição de medida provisória (urgência e relevância), que são controlados judicialmente apenas quando se configurar eventual abuso legislativo, e também de um controle das regras formais do sistema político quando presente eventual violação a direito subjetivo das minorias, o que só acontece na formação das comissões parlamentares de inquérito, embora no voto do ministro relator Carlos Britto possa ser extraído um início de ideia de que a formulação da pauta legislativa é matéria afeta à economia interna da Casa, portanto, interna corporis.

Há, então, na decisão em foco, uma real vontade de Constituição levada a efeito pelo Supremo Tribunal Federal, o que se verifica em outro caso considerado paradigma neste artigo.

Na Ação Direta de Inconstitucionalidade no $n^{0} .048-1 / \mathrm{DF}^{15}$ anteriormente citada, tendo por objeto a medida provisória, depois convertida em lei, que criava créditos extraordinários, a Corte, em apertada maioria, $6 \times 5$, entendeu, em franca revisão de sua consolidada jurisprudência, que poderia controlar a constitucionalidade de lei orçamentária e a criação de créditos extraordinários para verificar se estes cumpriam os requisitos constitucionais da relevância, da urgência e para atender a despesas imprevisíveis e urgentes, qualificadas pelo próprio texto constitucional como despesas decorrentes de guerra, comoção interna e calamidade pública.

Do ponto de vista jurídico, a decisão emitida, sem embargo da restrita maioria, foi com base em requisitos definidos expressamente na Constituição (art. 167, $\S 3 \circ$ ), o que permite afirmar que essas normas definidoras de conceitos podem ser consideradas possuidoras de significado próprio e constitucional, isto é, constituem-se elas mesmas padrões manejáveis judicialmente, quer dizer, postulados que podem ter a sua racionalidade verificável, o que representa uma secularização do político, desde que se pense que matéria alguma possa fugir ao controle judicial só porque tem origem divina, e, por outro lado, e portanto, diferenciando-se, doutrinariamente, dos denominados padrões manejáveis judicialmente que não estão expressos na norma constitucional e que por isso devem ser indicados pelos ministros da respectiva Corte Constitucional.

\footnotetext{
${ }^{14}$ Esse tipo de decisão judicial leva à conclusão de que o sistema jurídico e o sistema político atuaram de encontro à, no dizer de Lourival Vilanova, "dialética de posições e contraposições que é característica da estrutural conflitual do fato político", exatamente porque anularam essa mesma conflitualidade.

${ }^{15}$ Requerente: Partido da Social Democracia Brasileira (PSDB). Requerido: presidente da República, relator ministro Gilmar Mendes.
} 
A expressão padrões manejáveis judicialmente vem do direito constitucional norte-americano, lá onde a Suprema Corte aplica a doutrina das questões políticas para não analisar, no mérito, determinados casos jurídicos. Imuniza, de forma absoluta, decisões de governo que por uma razão ou outra não possuem o já citado padrão.

Em um artigo intitulado "Judicially manageable standards and constitutional meaning", Fallon Jr. (2006) descreve a distinção entre significado da norma constitucional e padrão manejável judicialmente, para com relação ao primeiro afirmar que a Corte realiza processo de especificação, e com referência ao segundo argumentar que se efetiva processo de implementação. Em análise da jurisprudência daquela Suprema Corte o autor enumera três categorias de considerações operativas que informam os critérios adotados nas decisões para se determinar o que é um padrão manejável judicialmente, inteligibilidade, desideratos práticos e valores levados em conta pela Corte para responder à questão de suficiência que permita a adjudicação.

Não é o caso, neste artigo, de se descrever todos os argumentos lançados por Fallon Jr. no artigo citado, até porque sua extensão é considerável e seu conteúdo, em maioria, se refere à técnica de interpretação constitucional existente no direito constitucional norte-americano, contudo, tais condicionantes não impedem a utilização de algumas ideias ali manifestadas no direito constitucional brasileiro, tudo na consecução de se lançar alguma luz no debate proposto.

O Supremo Tribunal Federal, embora não admita expressamente, flerta com a doutrina das questões políticas, quando decide que pode apreciar atos do Legislativo e do Executivo que firam garantias formais, o que, a contrario sensu, implica afirmar que quando esses atos não ferirem direitos e garantias formais não serão examinados pelo mesmo tribunal. A diferença para os casos jurídicos aqui perscrutados em comparação com aqueles veiculadores de uma questão política sui generis é que nos aqui descritos há norma constitucional possuidora de sentido expresso como que a solicitar: possuo padrão manejável, por favor, interpretemme. Nesses casos, o produto pode ser, e em geral o é, uma decisão consistente, pois além de ser inteligível a questão jurídica posta, não depende ele, ato decisório, de cognição a respeito, por exemplo, de matéria que esteja além da capacidade empírica da Corte, além de sua habilidade para gerar resultado previsível e além de sua capacidade para estruturar uma análise que em princípio poderia levar a resultados corretos. Em suma, produz imediatamente efeitos concretos ao impedir a atuação do político nos moldes em que o foi antes da cassação de seus atos.

Decisões como as que vêm de ser expostas não parecem causar maiores discordâncias teóricas no jurídico nem irresignações práticas no político, o que pode tornar os casos constitucionais de mesmo jaez, e uma vez decididos, em casos fáceis, em oposição aos mais famosos e citados hard cases, estes sim, de suas vezes, propiciadores de maior discussão tendo em vista sua complexidade. 
Esses temas rondam e acabam por desembocar na vulgata expressa pelo termo judicialização da política. Loewenstein (1957), já na década de 1950, alertou para o problema, afirmando que estabelecer uma Corte como supremo árbitro do processo de poder, este que é a parte central da "judicialização da política", converteria o sistema de governo em uma "judiciocracy". Finaliza argumentando que a judicialização do processo de poder seria exitosa apenas se nenhum interesse vital dos exercentes do poder fosse adversamente afetado. Esses argumentos, tomados em conta de consideração e aplicados à jurisprudência que se vem produzindo atualmente pelo Supremo Tribunal Federal, podem fornecer algumas relevantes observações a respeito do tema. A primeira delas refere-se ao fato de que haverá, sempre e sempre, um campo da política imune à apreciação judicial, por mais que essa ou aquela presidência do Supremo Tribunal Federal impinja eventual ativismo judicial à Corte, seja por meio de intervenções esporádicas e aleatórias nos processos de deliberação, seja mesmo quando vota, em ambos os casos tentando, com ou sem sucesso, "controlar" o decidido pela maioria, evento que, ao menos na Suprema Corte norte-americana é atribuição, construída pela praxe, inerente ao denominado chief justice.

A segunda delas é que um limite claro ao escrutínio judicial pode ser aquele relativo à competição dos partidos políticos pela tomada de poder, esta também se constituindo coração do processo político, e do qual já escrevia a respeito Schumpeter (1975) para, inclusive, tomar essa condicionante característica essencial da democracia, o que faz da imunização um princípio de preservação da própria democracia, argumento mais denso do que o simples apelo ao respeito ao princípio da separação de poderes. ${ }^{16}$

E a terceira delas é a imunização do próprio processo político como um todo, e não apenas de determinados atos tomados na sua normal condução, ao controle judicial, já que política significa algo mais que uma simples decisão da Mesa do Parlamento, que restrinja, formalmente, eventual direito da oposição, tornada, no jurídico, minoria.

De igual maneira ao caso anteriormente descrito, aqui também a Corte, a despeito de analisar requisitos formais expressos nos dispositivos constitucionais, produziu, com sua decisão, efeitos diretos na política material, contudo a interpretação levada a cabo teve por fundamento preceito explicitamente plasmado no texto constitucional, sem apelo a qualquer elemento situado em campo intelectivo não sujeito ao controle de verossimilhança.

\footnotetext{
${ }^{16}$ É o caso das Resoluções no 22.610/07 e nº 22.733/08, do Tribunal Superior Eleitoral, que tratam da fidelidade partidária e que já são objeto da Ação Direta de Inconstitucionalidade no 4.086, proposta pelo procurador-geral da República e sob relatoria do ministro Joaquim Barbosa, sob vários fundamentos, entre os quais, o de que aquele tribunal teria, indevidamente, legislado.
} 
Esses dois casos ilustram com bastante força de significação a confusão, teoricamente tratada por Bolingbroke no longínquo 1734, em sua famosa $A$ dissertation upon parties, entre Constituição e governo, criada aqui no país, por atos normativos advindos do político. Por Constituição ele entendia o conjunto de leis, instituições e costumes derivados de certos e fixados princípios da razão e dirigidos a certos e fixados objetos do bem público e que compõem o sistema geral com o qual a comunidade concordou ser governada. Por governo ele compreendia a particular condição de conduta na qual o dirigente maior e seus subordinados mantêm na administração dos negócios públicos. Apesar de conceitos distintos, Bolingbroke afirmou que o cidadão não pode ser amigo do governo e inimigo da Constituição, uma vez que se entenda que o governo é fundado pela última.

Outra não foi a compreensão de Thomas Paine (1984), que em seu livro Rights of man, especificamente na segunda parte que veio a lume em 1792, cujo título é Of constitutions, pergunta por qual razão constituições e governos são termos usados separada e distintamente, para responder que uma Constituição não é um ato de um governo, mas de um povo que constitui um governo, é propriedade da nação, e governo sem uma Constituição é poder sem um direito. Escrevendo no contexto do parlamentarismo inglês, o que é bastante apropriado a esta análise, desde que se pense que o instituto da medida provisória foi importado da experiência parlamentarista italiana e positivado na experiência presidencialista brasileira, Bolingbroke argumentava, já naquele distante tempo, que embora muita segurança para as liberdades seja provida, é a integridade que depende da liberdade e da independência do Parlamento que é a pedra de toque que mantém o todo reunido, e se ela é tocada ou removida, a Constituição cai em ruínas, e Paine escrevia que o governo representativo é liberdade.

O problema político da espécie normativa denominada medida provisória parece residir no fato de que é instituto moldado a fazer carreira no sistema parlamentarista, sistema onde o Parlamento é protagonista na condução da política, e que, uma vez implementado no sistema presidencialista, onde o papel principal de regente da política cabe ao presidente da República, causa um tipo de paralisia legislativa quando de sua utilização. Contudo, a crítica feita com relação à eventual ofensa ao Legislativo e/ou Parlamento vale, com muito maior força de argumento, para o sistema presidencialista, pois em nada se diferencia da primeira ao se levar em conta que a ofensa é contra a Constituição: fraude à Constituição na linguagem jurídica e ataque à instituição parlamentar na linguagem política.

$\mathrm{O}$ modo de funcionamento do sistema político aqui indicado, pelo qual o próprio sistema bloqueia sua comunicação, pode ter como causa certo desapreço pela Constituição, isto é, uma falta de vontade de Constituição, o que produziria a pouca ou quase inexistente força normativa da Constituição e, por consequência, a impossibilidade de se diferenciar entre governo e Constituição. Se não é errado 
argumentar com essas palavras, também não parece incorreto afirmar que a correção de rumos adotada por quem é competente para fazê-lo, no caso, o Supremo Tribunal Federal, é extraída do mesmo texto constitucional, o que demonstra uma certa força normativa a dele irradiar, ou seja, se não se vive o melhor dos mundos constitucionais possíveis no Brasil, de igual efeito não se vive o pior deles.

Os dois casos concretos decididos pelo Supremo Tribunal Federal e aqui analisados servem a dois propósitos: demonstrar, faticamente, como é possível a aplicação de posições intelectuais a respeito de temas constitucionais sobre a matéria sub judice, criando, dessa maneira, um novo e profícuo material jurídico a servir de manancial para a formação da teoria constitucional; se essa práxis referente à interpretação constitucional se institucionalizar, há espaço para se afirmar que o Supremo Tribunal Federal tem sido judicialmente ativo, e isso não porque lança mão de processos decisórios atinentes à política, mas simplesmente porque efetiva o controle de constitucionalidade. As duas formas de se alterar o texto constitucional produzem a sua adaptação à complexa realidade social, e aquele, uma vez adaptado, pode já evoluir.

\section{Relevância}

Descrito o processo pelo qual a Constituição pode ser considerada resiliente no sentido de se adaptar às mudanças feitas em seu texto, passa-se agora a analisar a sua relevância, se é ou não relevante à sociedade moderna e em que grau, se positiva a resposta à primeira indagação, essa relevância se manifesta.

Para que a descrição aqui empreendida seja adequada impõe-se uma análise, ainda que breve, do conceito de Constituição, que se configura no ponto de partida de qualquer ensaio no qual se pretenda descrever e, se for o caso, normatizar a respeito da relevância do texto constitucional.

A discussão a respeito do conceito atual de Constituição deriva da Antiguidade, se já se fazia presente no medievo ou se é produto genuíno da modernidade está há muito instaurada na teoria constitucional, menos na dogmática constitucional e mais numa teoria constitucional produzida pela ciência política. Os argumentos orbitam em torno da afirmação e da negação de que o conceito moderno de Constituição tem raízes na politeia dos gregos. McIlwain (1947:26) talvez tenha sido o precursor da polêmica ao afirmar que de todos os significados aos quais a palavra constituição é suscetível, o grego politeia conforma-se como o mais antigo, no que é seguido pela prestigiada Enciclopédia Britânica. ${ }^{17}$ Fioravanti (1999:14) argumenta

\footnotetext{
${ }^{17}$ Segundo Herbert John Spiro: "Aristotle's classification of the 'forms of government' was intended as a classification of constitutions, both good and bad. Under good constitutions - monarchy, aristocracy, and the mixed
} 
que o problema é mais simples do que deixa entender a crítica historiográfica e que por politeia deve-se compreender o instrumento conceitual do qual se serve o pensamento político do século IV na busca de uma forma de governo adequada ao presente. Saldanha (1983:102-103) se posiciona ao lado dos que negam a origem na antiguidade. Mohnhaupt (2002:6-9) escreve que o conceito de politeia foi decisivo para o desenvolvimento do conceito de Constituição na modernidade, embora ressalte que a tradução da palavra politeia pela de Constituição não deixe de ser problemática, pois Aristóteles tinha diante de seus olhos a situação constitucional da polis dos séculos IV e V, e portanto naquela época não se pensava em estado de direito, quando muito em teoria do Estado, enquanto Luhmann (1996:83-84), de sua vez, argumenta se tratar o conceito de Constituição de um conceito moderno oriundo do Setecento. Já para Stourzh (1988:35-54) o termo politieia foi traduzido para o inglês como commonwealth, polity ou government.

Assentado, então, que a ideia atual de Constituição é uma aquisição evolutiva da modernidade, tendo em vista diferenças específicas referentes às estruturas sociais vigentes na sociedade antiga e na sociedade moderna, impõem-se como modelos de discussão conceitos produzidos na própria modernidade.

Recorrente na teoria constitucional é a classificação empreendida por Loewenstein em seu livro Political power and the governmental process, ${ }^{18}$ título com trajetória bastante curiosa em sua tradução, pois foi traduzido para o alemão como Verfassungslehre e para o espanhol como Teoría de la Constitución. Nesse livro, no capítulo V, intitulado The Constitution, Loewenstein tenta elaborar uma classificação atualizada para aquele tempo, década de 1950, e para tanto, lança a ideia de se considerar ontologicamente a Constituição, abordagem ontológica essa que não condiz com a substância ou com o conteúdo, mas sim com a concordância da realidade do processo de poder com as normas constitucionais.

Dessa premissa decorrem três tipos: Constituição normativa; Constituição nominal; Constituição semântica. A normativa é aquela que, além de legalmente válida, e para ser real e efetiva deve ser plenamente observada por todos os seus destinatários, deve estar integrada na sociedade estatal; a nominal implica que as condições socioeconômicas militam contra, no respectivo tempo, a completa concordância das normas constitucionais com as exigências do processo de poder;

\footnotetext{
kind to which Aristotle applied the same term politeia - one person, a few individuals, or the many rule in the interest of the whole polis. Under the bad constitutions - tyranny, oligarchy, and democracy - the tyrant, the rich oligarchs, or the poor demos, or people, rule in their own interest alone" (1993:690).

${ }^{18}$ O subtítulo do livro é: "An analysis of the political power institutions and techniques of contemporary society from the viewpoint of political power as the core of all government" (1957). Em realidade essa classificação proposta por Loewenstein já tinha sido escrita no artigo também de sua autoria intitulado "Reflections on the value of constitutions in our revolutionary age".
} 
e a semântica é aquela cuja realidade ontológica é nada além da formalização da alocação existente do poder político em benefício dos que estão no poder e no controle da execução da maquinaria estatal.

Giovanni Sartori e Marcelo Neves reelaboram o conceito de Loewenstein a respeito da Constituição semântica, o primeiro no artigo cujo título é Constitutionalism: a preliminary discussion, ${ }^{19}$ em que propõe classificar as constituições em garantista, nominal e de fachada ou falsa. A primeira é aquela que contém dois básicos elementos: um plano de governo e uma declaração de direitos. A nominal ele designa a que Loewenstein denomina de semântica, utilizando-se dos mesmos termos, é aquela cuja realidade ontológica é nada mais que a formalização do poder político em favor dos que governam. E a Constituição de fachada é aquela que tem apenas a aparência de Constituição verdadeira, contudo, é sempre desconsiderada, especialmente naquilo que é referente aos direitos fundamentais.

Neves argumenta que a Constituição semântica de Loewenstein é descrita de forma mais adequada pelo termo instrumentalista, pelo qual os donos do poder dispõem dela à sua mercê por ser ela um instrumento de dominação.

A classificação de Loewenstein, a despeito de ser ainda apenas ligada à ideia de limitação do poder, de respeito aos direitos individuais, e sem embargo da correção que lhe fazem Sartori e Neves, pode, todavia, ser considerada válida em um aspecto bastante importante, se não o mais importante, atinente à concretização do texto constitucional, e que é exatamente a atuação da política afinada com a Constituição.

Essa é a preocupação que perpassa por toda a descrição do autor e que, se trazida aos tempos atuais, especificamente no contexto de realidades semiperiféricas, de cujo exemplo o Brasil é forte ilustração, pode contribuir para uma maior compreensão dos eventos de alteração constitucional ocorrentes.

A insuficiência da classificação proposta por Loewenstein se relaciona ao fato de que uma Constituição, para ser concretizada, exige uma descrição que vá além daquela que indique que o texto constitucional deva possuir um plano de governo e uma declaração de direitos. Vale dizer, a teoria constitucional não pode mais se satisfazer apenas com um enfoque que divida a Constituição em conteúdo funcional e conteúdo ideológico. A classificação proposta, então, é validada pelo seu contrário, isto é, há sempre a necessidade de um, para citar um termo psicanalítico, "ambiente facilitador" ${ }^{20}$ para que a norma constitucional se concretize na

\footnotetext{
${ }^{19}$ A mesma classificação foi ratificada no artigo "Constitución" (2007:13-27).

${ }^{20}$ Quem criou e trabalhou com esse termo foi o psicanalista inglês Donald W. Winnicott, termo esse que, no comentário autorizado de Conceição A. Serralha de Araújo, assim se expõe: "ambiente facilitador: referente às condições físicas e psicológicas que favorecem esse desenvolvimento (desenvolvimento global do indivíduo)". Como consequência do transporte desse conceito da psicanálise para a teoria constitucional, pode-se considerar a Constituição como a "mãe ambiente, que são as condições psicoló-
} 
realidade, contudo, há casos em que, para que isso aconteça, é necessária a imposição da mudança do respectivo texto, seja porque a "ideologia" que norteou o processo constituinte já não mais existe ou ao menos não se impõe como das mais importantes, seja porque no tempo presente há inumeráveis tipos de ideologias a se esgrimir e a exigir reconhecimento constitucional, o que parece ser a real luta por reconhecimento.

Há aqui uma possibilidade de identificação do ambiente facilitador com o conceito de democracia. Mesmo Winnicott (1986:239-259) se aventurou a fornecer um conceito de democracia, ligado também à sua teoria sobre o ambiente facilitador. No artigo "Some thoughts on the meaning of the word 'democracy'" Winnicott se aventura, na condição de psicanalista, a contribuir com ideias sobre democracia, o que para ele tem a ver, necessariamente, com o amadurecimento da sociedade, maturidade que é atingida quando não há interferência do exterior sobre o que ele denomina de ordinary good homes e traduzido pela linguagem psicanalítica como lares suficientemente bons, que são aqueles capazes de gerar o fator democrático nato, e é essa não interferência que promove a democracia, pois deixa às famílias a possibilidade de estabelecerem relações adequadas entre os pais e os filhos.

Na passagem de um conceito de democracia que privilegia o espaço privado a um que coloque ênfase no espaço público, movimento esse muito mais de complementaridade e muito menos de exclusão de um pelo outro, vem à tona a ideia de Sartori, para quem, numa revisão da teoria democrática, democracia é representada pelo respeito da majority rule pelos minority rights.

Da análise conjunta dessas duas conceituações pode-se afirmar que uma depende da outra para se estabelecer e ter uma duração: a primeira mais centrada nas relações privadas e na formação do cidadão com consequências imediatas na comunidade, e a segunda dirigida às relações de natureza pública com consequências mais imediatas na sociedade. A primeira tem a ver com o grau de informação daqueles que compõem o corpo eleitoral e perante os quais aquele que decide é responsável; a segunda condiz com a luta pelo reconhecimento de direitos e garantias a ser travada nas arenas política e jurídica. E é nesse caldo teórico que a relevância da Constituição vai se manifestar, servindo de parâmetro à atuação dos sistemas jurídico e político.

A necessidade de se operar a descrição atualizada dos eventos que informam a mudança do texto constitucional é mais forte quanto mais se pensa em que se deva evitar o que Sartori (1984:497-499) chama de retrodicção, que é a aplicação da ideia de constitucionalismo à Roma e à Grécia, o que inevitavelmente projeta 
um padrão moderno de referência a um mundo muito diferente e distante ou, em palavras mais atuais, menos complexo.

Não se trata de desprezar as concepções clássicas a respeito de Constituição, mas sim de descrevê-las e apontar suas deficiências se aplicadas à sociedade moderna. Dieter Grimm no artigo de nome "Il futuro della costituzione", traça um quadro pessimista sobre a capacidade regulatória da Constituição, e isso porque o progresso técnico-científico gera medo do futuro e produz o direito humano à segurança, o que impõe ao Estado criar mecanismos de prevenção, antes que de comando e coerção, e que se manifestam indiretamente, tal como o dinheiro, utilizado em penas pecuniárias e tributos.

No Brasil, a Constituição tem que manejar dois conceitos de direito humano à segurança, seja aquele relacionado à segurança contra o risco causado pelas aceleradas inovações tecnológicas, seja o referente à segurança pública, de vez que nem mesmo este direito cronologicamente anterior foi assegurado ainda ao povo.

Na desincumbência dessas tarefas, o Supremo Tribunal Federal parece se sentir mais à vontade quando decide sobre direitos individuais, mesmo quando estão em jogo aqueles ameaçados pelo risco, e daí a aplicação ou não de princípios como o da precaução e o da prevenção. Já em relação aos direitos sociais, cuja decisão, quase sempre, tem que desprezar a aplicação do clássico programa condicional que informa o jurídico, para se aplicar o programa de fins caracteristicamente atinente ao político, há dificuldades de toda ordem, especialmente aquela representada pela multiplicidade de possibilidades de decisão e seu não enquadramento automático no esquema condicional se/então. O problema parece estar mesmo na especialização funcional dos sistemas, ainda que se deseje a realização do contrário.

A diminuição da capacidade regulatória da Constituição é causada, então, pela manutenção de seu texto por assim dizer "clássico", em que se positivam normas de organização do Estado e de direitos fundamentais, numa sociedade que já não é mais aquela em que o modelo ou padrão do mesmo texto foi criado. E se nas sociedades centrais da modernidade o fosso entre texto e realidade já se mostra extenso, maior ainda é ele nas sociedades semiperiféricas, o que produz o comprometimento de uma relevância talvez numa gradação elevada do texto constitucional para a própria sociedade.

A distância entre texto e realidade tanto mais aumenta quanto mais se pensa na aceleração do tempo social e dos eventos que se materializam na sociedade, dos quais são fortes exemplos as questões previdenciárias, ecológicas e de saúde, as quais, ainda que discutidas, votadas e positivadas na Constituição, quando não apreciadas pelo simples fato de nelas não se pensar à época da elaboração do respectivo texto porque elas então não existiam, não são passíveis de aferição e controle por qualquer instituição, seja pelo Parlamento, seja pelo Supremo Tribunal Federal. Falta, para tanto, base teórica e empírica, e sobra incerteza. Texto e 
realidade, então, separam-se, na sociedade moderna e reflexiva, pela temporalização do tempo.

Esse evento, todavia, não torna a Constituição, como num eterno retorno à concepção de Lassalle, um mero pedaço de papel, pois se é certo que a sua relevância como instituição possibilitadora da ordem social sofre diminuição em grau, ela não desaparece por completo, posto que na quase maioria dos temas sensíveis à sociedade seu texto é invocado, seja na forma de norma-parâmetro para se aferir a adequação do ordenamento infraconstitucional a ele, texto constitucional, seja na forma de norma-parâmetro a ser emendada pelo procedimento autologicamente estabelecido nele mesmo, texto constitucional.

Daí não se poder considerá-la, apenas, como forma de organização da polis, já que suas normas positivam muito além de uma singela compreensão segundo a qual se deve organizar o poder e proteger os direitos fundamentais; deve-se, além disso, positivar normas que assegurem, publicamente, o processo de deliberação a ser levado a cabo tanto pelo Parlamento quanto pelo Tribunal Constitucional.

Os procedimentos de deliberação existentes na política e no direito são distintos entre si. No Parlamento o fato das proposições passarem pelo crivo das comissões e pelas fases de discussão e votação costumam prover as matérias de um acréscimo de sentido, o que se reflete na emissão e sopeso de visões de mundo em número maior do que a presente na deliberação levada a cabo quando das decisões emitidas pelo Supremo Tribunal Federal, até porque é na instituição política que se fazem presentes as ideologias existentes na sociedade, enquanto na Corte Constitucional se opera uma verdadeira redução do campo de incidência dessas mesmas ideologias. O resultado a ser obtido nesses procedimentos é a produção de consensos e dissensos fortes na política e de consensos e dissensos fracos no jurídico, a despeito de se denominar a este último de exercício de uma racionalidade argumentativa, ainda que levado a efeito em audiência pública.

A distinção toma corpo ao se pensar que no político a deliberação é tomada sem base em estruturas de repetição, e no jurídico as estruturas de repetição marcam sua história. Talvez as decisões produzidas no jurídico sejam mais consistentes exatamente pelo fato da presença da redundância. Temporalmente há economia de tempo no jurídico, contudo, deliberações tomadas com base em eventual precedente representado pela súmula vinculante tendem a empobrecer a racionalidade do próprio processo de deliberação, quando então nem mais as ideologias que já sofreram um reducionismo em sua manifestação estariam presentes, o que já foi afirmado pelo Justice Stevens quando da decisão proferida no caso jurídico sobre a injeção letal como método de execução de pena de morte referente à lei do Estado do Kentucky. ${ }^{21}$

\footnotetext{
${ }^{21}$ Baze v. Rees, 553 US (2008:8), de seu voto.
} 
A relevância do texto constitucional, no quadro aqui desenhado, tem a ver com as condições de possibilidade do cumprimento de sua função, e a consideração que se vai fazer a respeito dessa mesma relevância depende da perspectiva adotada pelo observador e do que ele compreende por função. Segundo Manoel Gonçalves Ferreira Filho, a Constituição possui 10 funções. Já para Luhmann (2002:540-541), a Constituição é o acoplamento estrutural entre os sistemas jurídico e político e nessa condição o que faz é apenas incrementar as comunicações entre esses mesmos sistemas.

Dependendo de qual descrição se adotar, a Constituição continuará ou não a ter relevância. Na concepção de Luhmann há pouco espaço para que se confira capacidade regulatória ao texto constitucional na sociedade mundial, e isso mesmo a despeito de se tentar normatizar formatos de estados, em particular o estado de bem-estar social. A radicalidade de sua concepção parece produzir mesmo efeitos na interpretação constitucional, que já não deveria mais possuir princípios próprios e distintos da interpretação do ordenamento infraconstitucional. Essa concepção pode até ter algum eco na sociologia, mas na dogmática constitucional sua utilidade é igual a zero, pois é a própria defesa do texto constitucional que impõe interpretar a Constituição lançando mão de técnicas próprias. E a defesa do texto constitucional, de sua vez, prova sua resiliência e sua relevância, e pode ser alçada à conditio sine qua do funcionamento do sistema jurídico, o que engloba tudo o que está neste artigo.

Ferreira Filho faz mero trabalho de citação do que escreve Canotilho e peca pela falta de originalidade. É absolvido pela repetição de hábito que toma conta da teoria constitucional brasileira. $\mathrm{O}$ argumento pelo qual se atribui tantas funções à Constituição traz consigo enorme carga de risco de que ela mesma não consiga cumprir o telos embutido nesse ainda finalístico conceito de função. Mais adequado, então, seria conferir a ela a protagonização de alguns papéis, talvez os mais complexos, a ser desempenhada nas denominadas questões constitucionais par excellence.

\section{Conclusão}

Se há um excepcionalismo norte-americano, pode-se afirmar que há, também, uma especificidade brasileira, representada pela existência simultânea da modernidade e da barbárie, da civilização e da não civilização, da autopoiese dos sistemas funcionais da sociedade e da alopoiese desses mesmos sistemas e que faz com que a conclusão de todo trabalho que se pretenda científico dedique algumas linhas à descrição do que ocorre no país, o que, se por um lado produz o enfraquecimento de um suposto caráter heurístico de qualquer esboço 
de pensamento, por outro ressalta a possibilidade de aqui fazer vingar padrões civilizatórios já testados em outros lugares ou mesmo de criar ideias próprias a respeito de problemas próprios. Daí a análise de alguns casos jurídicos decididos pelo Supremo Tribunal Federal.

O mundo vive o que se convenciona denominar democracia qualificada, pela qual os direitos humanos são ligados à separação de poderes, fórmula bastante simples de Höffe (2005) e que, no Brasil, ainda não se manifestou por completo. Isso equivale a dizer que as estruturas sociais ainda não se adequaram à ideia de modernidade vigente nos países centrais. $\mathrm{O}$ desrespeito à dignidade humana representado pelos altos índices de violência e pobreza e a atual luta de setores da excludente sociedade brasileira contra a implementação de políticas de inclusão não universalistas refletem a dificuldade de se introjetar mudanças na autorreprodução histórico-social.

A política, de sua vez, fecha-se em uma espécie de autismo e faz de seu cotidiano a reprodução de práticas pouco modernas, comunicando-se, quando isso acontece, por meio de escândalos. Resta o jurídico como desaguadouro de todas as frustrações causadas pela concretização da política pequena. Esse quadro talvez seja reflexo do processo de institucionalização ainda não acabado e no qual os papéis protagonizados por esse ou outro sistema ainda estejam em acomodação, o político ainda levando tempo para funcionar mais de acordo com o que preceitua a Constituição e o jurídico ainda procurando saber quem ele próprio é e quais as suas funções.

Nem seria mais o caso de se indagar a respeito de uma suposta força revolucionária da Constituição, se teria ela capacidade para mudar estruturas sociais existentes ao tempo de sua promulgação, ${ }^{22}$ de vez que a brasileira faz aniversário de 20 anos. A mudança dessas mesmas estruturas parece depender de outro tipo de ação, ou ao menos de uma ação integrada, e não isolada, e que parta das instituições da sociedade.

Em estudo feito sobre a alocação do poder de decisão, se deferido diretamente ao povo (democracia direta), a representantes responsáveis perante o eleitorado (chamados políticos) ou a representantes não responsáveis perante o eleitorado (juízes), Maskin e Tirole (2004:1034-1054) chegaram à conclusão de que a não-responsabilidade é mais desejável quando o eleitorado não é informado sobre a ação ótima das instituições (ambiente não facilitador), além do que a discricionariedade dos representantes não responsáveis deveria ser mais limitada do que a dos responsáveis e que a não responsabilidade é preferível quando as preferências da maioria devem infligir grandes e negativas externalidades sobre a minoria (conceito revisitado de democracia).

\footnotetext{
${ }^{22}$ O mesmo pensa Paul Bastid (1985:184).
} 
A primeira conclusão, se aplicada no contexto nacional, permite a dedução de que o Supremo Tribunal Federal deve continuar a exercer seu poder na linha do que vem fazendo, isto é, decidindo com a marca da inovação geral e vinculante, sendo, portanto, ativo judicialmente, desde que se tome como parâmetro de comparação a desinformação que ainda impera na sociedade brasileira, ação essa que também tem que ter limites, sob pena de se comprometer a própria democracia, limites esses que devem ser construídos ao longo do tempo de amadurecimento das próprias instituições e que pode ter na doutrina das questões políticas um sinal adequado; a última conclusão é em relação à função de garantia da Corte Constitucional, mais ligada à preservação das liberdades clássicas dos modernos, e que é mais aceita pela comunidade onde se travam os debates.

O aperfeiçoamento desses processos de institucionalização rumo a um ótimo desempenho depende, entre outras condicionantes, da capacidade de aprendizagem dos sistemas político e jurídico: do primeiro se espera uma atuação mais constitucional, isto é, mais de acordo com as regras dos jogos democráticos que se encontram plasmados no respectivo texto; do jurídico se espera uma atuação menos suplementar e mais complementar à atividade política, portanto, que ambos sejam cognitivamente abertos, tudo na consecução de se preservar a própria democracia.

Em suma, o sistema político estabelece uma relação com o jurídico, e se o primeiro apresenta falhas em seu funcionamento, o segundo entra em cena tentando consertar as ações ou as omissões inconstitucionais: o limite fica por conta da proibição de legislar, pois se a lei tem caráter geral é porque ela deve ser feita pelo Parlamento; se pela Corte Constitucional, perde sua principal característica imanente que é a generalidade, já que ela, a generalidade, não consegue ser refletida em decisão onde se manifesta uma não generalidade, mas sim parciais visões de mundo, em geral de viés moralizador. Essa relação, diretamente proporcional e normativa, permite o surgimento de sistemas heterárquicos, tudo propiciado pela Constituição, ainda hoje e por isso mesmo, resiliente e relevante à sociedade

\section{Referências}

ARAÚJO, Conceição A. Serralha. O ambiente em Winnicott. Winnicott E-Prints, v. 4, n. 1, p. 21-34, 2005.

BASTID, Paul. L'idée de Constitution. Paris: Economica, 1985.

BOLINGBROKE, Henry St. John. A dissertation upon parties. Political writings. Cambridge: Cambridge University Press, 1997. 
CALVINO, Italo. O mundo é uma alcachofra. Por que ler os clássicos. São Paulo: Companhia das Letras, 2002.

CORWIN, Edward S. The Constitution as instrument and as symbol. The American Political Science Review, v. 30, n. 6, p. 1071-1085, Dec. 1936.

FALLON JR., Richard H. Judicially manageable standards and constitutional meaning. Harvard Law Review, v. 119, p. 1274-1332, 2006.

FERREIRA FILHO, Manoel Gonçalves. Aspectos do direito constitucional contemporâneo. São Paulo: Saraiva, 2003.

FIORAVANTI, Maurizio. Costituzione. Bologna: Il Mulino, 1999.

FREUD, Sigmund. O futuro de uma ilusão. Obras Completas, v. 21. Rio de Janeiro: Imago, 1996.

HÖFFE, Otfried. A democracia no mundo de hoje. São Paulo: Martins Fontes, 2005.

HOLMES, Stephen. Precommitment and the paradox of democracy. In: ELSTER, Jon; SLAGSTAD, Rune (Eds.). Constitutionalism and democracy. Cambridge: Cambridge University Press, 1993.

KMIEC, Keenan D. The origin and current meanings of "judicial activism". California Law Review, v. 92, p. 1441-1477, 2004.

KOOPMANS, Tim. Courts and political institutions. Cambridge: Cambridge University Press, 2003.

LOEWENSTEIN, Karl. Reflections on the value of constitutions in our revolutionary Age. In: ZURCHER, Arnold J. (Ed.). Constitutions and constitutional trends since World War II. New York University Press, 1955.

. Political power and the governmental process. The University of Chicago, 1957.

LUHMANN, Niklas. El derecho de la sociedad. México: Universidad Iberoamericana, 2002.

. Teoría política en el estado de bienestar. Madrid: Alianza Universidad, 1997.

LUHMANN, Niklas. La Costituzione come acquisizione evolutiva. In: ZAGREBELSKY, Gustavo; PORTINARO, Pier Paolo; LUTHER, Jörg . Il futuro della costituzione. Torino: Einaudi, 1996.

MASKIN, Eric; TIROLE, Jean. The politician and the judge: accountability in government. The American Political Science Review, v. 94, n. 4, p. 1034-1054, Sept. 2004.

McILWAIN, Charles Howard. Constitutionalism: ancient \& modern. Ithaca: Cornell University Press, 1947. 
MONHAUPT, Heinz. Verfassung I: konstitution, status, leges fundamentales von der antik bis zur aufklärung. In: MONHAUPT, Heinz; GRIMM, Dieter. Verfassung: zur geshichte des begriffs von der antike bis zur gegenwart. Berlim: Duncker \& Humblot, 2002.

NEVES, Marcelo. A constitucionalização simbólica. São Paulo: Martins Fontes, 2007.

PAINE, Thomas. Rights of man. New York: Penguin Books, 1984.

POSNER, Richard A. A political court. Harvard Law Review, v. 119, n. 54, p. 31-102, nov. 2005.

PRADO JR., Bento. O relativismo como contraponto. In: Erro, ilusão, loucura. São Paulo: Editora 34, 2004.

SALDANHA, Nelson. Formação da teoria constitucional. Rio de Janeiro: Forense, 1983.

SARTORI, Giovanni. Constitutionalism: a preliminary discussion. The American Political Science Review, v. 56, n. 4, p. 853-864, Dec. 1962.

. Comments on Maddox. The American Political Science Review, v. 78, n. 2, p. 497-499, June 1984.

. Constitución. In: Elementos de teoría política. Madrid: Alianza Editorial, 2007a.

. Democracia. In: Elementos de teoría política. Madrid: Alianza Editorial, 2007b.

SCHUMPETER, Joseph A. Capitalism, socialism and democracy. New York: Harper Perennial, 1975.

SILVA, Paulo Thadeu Gomes da. Questões políticas. 2005. Tese (doutorado) - São Paulo, Pontifícia Universidade Católica.

SPIRO, Herbert John. Constitution and constitutional government. 15. ed., v. 16, 1993.

STOURZH, Gerald. Constitution: changing meanings of the term. In: BALL, Terence; POCOCK, J. G. A. (Eds.). Conceptual change and the Constitution. University Press of Kansas, 1988.

TATE, C. Neal; VALLINDER, Torbjörn (Eds.). The global expansion of judicial power. New York: New York University Press, 1995.

VILANOVA, Lourival. Política e direito: relação normativa. In: Escritos jurídicos e filosóficos. São Paulo: Axis Mundi, 2003.

WINNICOTT, Donald W. Some thoughts on the meaning of the word 'democracy'. Home is where we start from. London: Penguin Books, 1986. 